\title{
LÍVIO LEVI E O PIONEIRISMO NO ENSINO DO DESIGN
}

\author{
Ana Paula Coelho de Carvalho \\ SENAC/SP \\ anacoelho.arq@gmail.com
}

\begin{abstract}
Resumo: O presente texto é resultado de uma investigação sobre as origens do ensino de design, no âmbito de bacharelado na cidade de São Paulo, tomando-se como referências: documentação primária dos cursos, bibliografia específica, contextos históricos e depoimentos dos personagens que participaram de suas histórias. Esta pesquisa é parte integrante de uma indagação maior que se objetivou conhecer os princípios do ensino paulistano do design, resgatar a história da implementação destes cursos e verificar possíveis relações entre as primeiras instituições e seus personagens, sendo um dos representantes encontrados o professor Lívio Levi. Arquiteto por formação, Levi desenvolveu relevantes pesquisas sobre o ensino do design e atuou profissionalmente nesse campo por meio da academia, entidades de classe e desenvolvimento de projetos, destacando-se a área de iluminação, e cuja história é objeto deste artigo.
\end{abstract}

Palavras-chave: São Paulo, design, ensino

\begin{abstract}
This work presents a research into the origins of the teaching of design at college in São Paulo city having as a reference: basic course, especial bibliographies, historical context and the talks of the people engaged in those facts. This way one is a part of the biggest research and it aims to the very beginning of the design teaching in São Paulo, rescues the setting up of the teaching and verify the probable relations among the early Institutes and their personages. One of these is the architect and teacher Livio Levi, who developed relevants researches on teaching of design and worked in lighting. His history is object of this article.
\end{abstract}

Keywords: Sao Paulo, design, teaching

\section{INTRODUÇÃO}

À procura pela origem do ensino paulistano de design, realizou-se um levantamento cronológico a fim de se identificar as primeiras instituições e os personagens envolvidos na construção da academia desse campo na cidade de São Paulo. Sob esse intuito, levantou-se das grades curriculares dessas escolas nos 
primeiros anos de seus cursos, ainda chamados de Desenho Industrial (e Comunicação Visual, quando tratavam-se de habilidades) a partir de documentação oficial das diretrizes para o ensino de design da época, bibliografia dos cursos, além de documentos internos das escolas e depoimentos de ex-alunos e ex-professores participantes do período abordado em pesquisa.

Com os dados apreendidos, procurou-se usar o referencial teórico sobre estudo da formação profissional e estudo de currículo em design para caracterizar as especificidades de cada curso. Diante dos fatos investigados e sob a finalidade de identificar possíveis relações entre as instituições nesse momento de implantação dos primeiros cursos de design na capital paulista, nas dimensões do currículo, da formação profissional oferecida e do corpo docente, alguns nomes receberam relevância enquanto outros foram descobertos. Por meio da história oral, em primeira instância, e, principalmente de levantamento em documentos de acervos particulares, em um segundo momento, destacamos o nome de Lívio Levi. À procura de identificar a formação profissional pretendida das escolas pioneiras e em posse das fontes documentais e orais, as disciplinas oferecidas e os currículos foram comparados e algumas relações sociais, acadêmicas e profissionais foram estabelecidas. Em meio ao cruzamentos de dados, Lívio Levi fez-se presente por sua participação em instituições, eventos e pesquisas, profissionais e acadêmicas, nos primeiros anos do ensino do design paulistano, e é apresentado no referido texto como um dos pioneiros desse campo, em destaque para sua produção no campo da iluminação.

\section{DESENVOLVIMENTO}

Lívio Edmondo Levi nasceu em Trieste, Itália, em 19 de março de 1933 e faleceu precocemente na cidade do Rio de Janeiro no ano de 1973. Ele estudou o Ginásio e o Colegial no Instituto Mackenzie, onde cursou a Faculdade de Arquitetura da Universidade Mackenzie, formando-se em 1956. Nesta Instituição, também realizou o curso complementar de Urbanismo e Planejamento .

Logo após a graduação, iniciou suas atividades profissionais como integrante da equipe dos arquitetos Henrique Mindlin e Giancarlo Palanti o que Ihe permitiu desenvolver uma série de projetos arquitetônicos de edifícios residenciais e comerciais, públicos e privados, até meados da década de 1960.

Levi dedicou-se também às questões profissionais e acadêmicas do design, área que the fez ganhar projeção nacional, principalmente com seus objetos voltados a iluminação e metais sanitários. Para ampliar seus conhecimentos neste campo, o professor buscou referências nacionais e internacionais o que se reflete na importância de sua participação nas atividades relacionadas ao desenho industrial neste período. Dentre os cursos de design que realizou estão as Disciplinas I e II da pós-graduação da FAU/USP: Metadesign, em 1965, e Introdução à Teoria da Comunicação, em 1966, respectivamente.

Anteriormente a estes, outra colaboração do professor Levi nas discussões do campo foi sua participação no I Seminário de Ensino de Desenho Industrial ocorrido na mesma FAU/USP (de 09 a 13 de novembro) em 1964, assim registrado pelo primeiro número da revista Produto e Linguagem ${ }^{1}$ :

1 Produto e Linguagem. São Paulo: Associação Brasileira de Desenho Industrial, 1o trimestre, 1965. Ano 1, n.1. 
O arquiteto Lívio E. Levi abriu o Seminário, expondo a situação do ensino do Desenho Industrial nos Estados Unidos, de onde regressara há pouco. Sua exposição cingiu-se praticamente a um dos mais prestigiosos estabelecimentos norte-americanos do gênero: o MIT [Massachusetts Institute of Technology].

Lívio Levi foi representante de entidades brasileiras, tanto de arquitetura quanto de desenho industrial, principalmente durante a década de 1960 . No Instituto de Arquitetos do Brasil - IAB, Levi foi um dos representantes (2 Secretário do Conselho Diretor), de 1963 a 1965, quando compôs o Seminário "O Homem na Paisagem Paulistana", em 1964, e ainda convocou e participou do Seminário "Subsídio ao Encaminhamento do Plano Diretor de São Paulo". Neste mesmo ano, viaja pelo Instituto aos EUA, para pesquisar sobre desenho industrial no Illinois Institute of Technology - $I I T^{2}$, em que recolhe uma série de informações sobre o ensino daquela escola, considerada referência inclusive pela academia brasileira do design.

Na Associação Brasileira de Desenho Industrial - ABDI, Levi exerceu o cargo de Diretor de Planejamento nos anos de 1966 e 1967, e Diretor de Divulgação no biênio 1968/1969. Esta associação já o havia chamado, em 1964, para ser relator do Seminário de Ensino de Desenho Industrial, e em 1965, convidou-o ${ }^{3}$, junto com Décio Pignatari ${ }^{4}$ para representar o Brasil em um dos mais importantes eventos de desenho industrial mundial, o International Council of Societies of Industrial Design - ICSID. Este episódio é o primeiro de uma série de encontros que permitiram a interlocução entre os pioneiros do ensino de design e a comunidade do campo internacional.

A partir daquele ano, Levi integrou a comissão que representou o Brasil também nos dois encontros posteriores (1967 e 1969). Ocasiões que o permitiram visitar outras escolas da Europa e América do Norte, além dos locais destes eventos, e possibilitaram o contato e a coleta de dados com os representantes da academia destes continentes que contribuíram significativamente para novas visões brasileiras no campo do design.

Os júris de concursos voltados ao design nacional também tiveram a presença de Lívio Levi como o Prêmio Lúcio Meira, em 1964/1966, e o Prêmio Roberto Simonsen de Desenho Industrial, nos anos 1965, 1966, 1967 e 1969, que the corou com o Certificado da Boa Forma em 1964 (Figura 1), e o convocou para representar o Instituto Mackenzie no ano de 1965. Além desse, Levi recebeu reconhecimento com diversas premiações, destacando-se o Prêmio Especial do Júri - II Bienal de Artes Aplicadas - Punta del Este, 1967, o Prêmio IAB - SP "Desenho Industrial Aplicado à Arquitetura" - 1967, e ainda o Prêmio Especial do Júri "Hors Concours" no Salão Eletrobrás do Museu de Arte Moderna do Rio de Janeiro, 1971.

Lívio Levi foi também um dos primeiros arquitetos a atuar no campo artístico de desenho de joias dos anos 1960, conforme aponta Nadur (In: Braga; Moreira, 2012). Ele ainda participou como convidado na Bienal Internacional do Rio de Janeiro (Desenho Industrial), no Museu de Arte Moderna - MAM/RJ em 1968, 1970 e 1972.

\footnotetext{
2 O IIT, chamado de New Bauhaus, foi fundado em 1937 por Moholy Nagy, ex-diretor da escola alemã.

3 In: BRAGA, 2007.

4 Décio Pignatari (Jundiaí, 20 de agosto de 1927 - São Paulo, 2 de dezembro de 2012). Professor, escritor e estudioso da semiótica.
} 
Como docente Levi foi regente da Cadeira de Desenho III - Desenho Industrial do 3o ano da Faculdade de Arquitetura Mackenzie, entre os anos de 1964 a 1970. Na Fundação Armando Álvares Penteado - FAAP foi professor titular da disciplina de Projeto do Curso de Desenho Industrial entre 1970 e 1973.

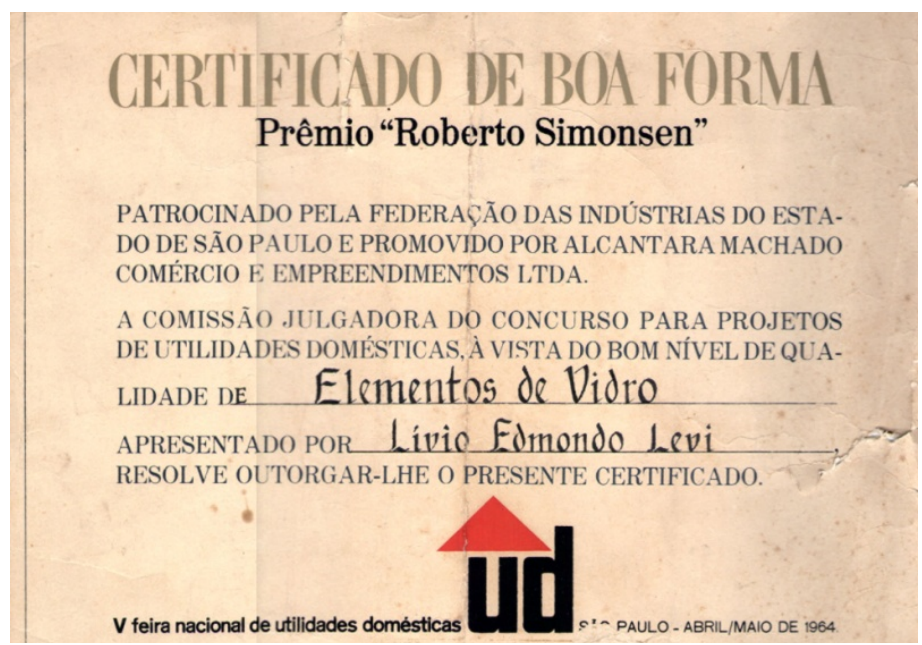

"Figura 1 - Certificado de Boa Forma".

Fonte: Acervo de Marília Levi.

Sua obra é uma coleção exemplar de projetos arquitetônicos e de desenho industrial. Este segundo pode ser representado por: maçanetas para as Ferragens Acquila, objetos de vidro para a indústria San Marco, metais sanitários, poltronas e cadeiras de escritório para a indústria Escriba e objetos voltados à iluminação.

Dentre os produtos de sua autoria, as luminárias são peças que se diferenciam pela forma inovadora e tecnologia dos materiais explorados no período, das quais se destacam as instaladas no Ministério das Relações Exteriores, em Brasília (1966) e no Jockey Clube do Rio de Janeiro (1973).

\subsection{Instituto Presbiteriano Mackenzie e a disciplina de Desenho Industrial}

Como apontado, a importância de Levi vai além de sua atuação como professor. O contato estabelecido com personagens do design internacional, entre eles Tomas Maldonado, Jay Doblin e Misha Black e a visita a uma série de escolas de design na Europa, Estados Unidos e Canadá ${ }^{5}$, possibilitou a ele organizar sua disciplina, dentro da Faculdade de Arquitetura, em coerência com as questões do desenho industrial, de que tomou conhecimento.

Assim, em 1964 o professor Levi é nomeado regente da Cadeira de Desenho do 3o ano do curso de Arquitetura da Universidade Mackenzie, a única que passa a ser dedicada ao desenho industrial dentro de todo o curso por decisão do professor.

Nesta investigação sobre o campo e aperfeiçoamento didático, Levi tinha a intenção de "transmitir a necessidade de desenhar bem qualquer produto dentro da metodologia da arquitetura, porém com uma visão de processos completamente diferente da arquitetura.", segundo palavras de Esther Stiller ${ }^{6}$, ex-aluna, arquiteta e herdeira do escritório de Levi. Para ela, o objetivo dos trabalhos propostos era

\footnotetext{
5 Estes locais podem ser identificados em anotações feitas pelo próprio Lívio Levi em documentação encontrada nos acervos familiares. [Fonte: Acervo de Marília Levi]

${ }^{6}$ Entrevista de Esther Stiller concedida à autora em 28/08/2011.
} 
condizente com os procedimentos típicos da produção de objetos em escala menor que os da arquitetura, assim descrito:

[...] uma noção clara de como são os procedimentos industriais versus a maneira artesanal que era construído o edifício, como por exemplo, os caixilhos, louças sanitárias, divisórias produzidos de uma concepção industrial diferentemente de como era produzida a arquitetura, como tijolo em cima de tijolo. ${ }^{7}$

Dessa forma, na disciplina de DI do Mackenzie, o professor propunha tarefas que alinhavam o processo industrial ao objeto na dimensão do usuário, assim caracterizado por Stiller ${ }^{8}$ quanto à prática das aulas:

A dinâmica do curso era muito simples, com temas e trabalhos de desenvolvimento rápido. Cada dois meses era um trabalho que tinha um tema a ser desenvolvido. A metodologia era simples, no sentido de buscar a tecnologia da produção. Chegamos a visitar uma ou duas fábricas. Fazíamos desenhos e perspectivas.

As palavras da ex-aluna apontam para um grau de detalhe a que Levi se dedicava e a importância da representação nas suas aulas, características do seu trabalho ao longo do tempo, como pode ser visto nos objetos que projetou.

As declarações da arquiteta sugere-nos que a disciplina de Lívio Levi abordava o desenho industrial com o intuito de discorrer também sobre a arquitetura industrializada, outra questão levada pelo professor Levi ao Mackenzie como verificado em suas notas ${ }^{9}$.

\subsection{A Proposta de um curso independente de Desenho Industrial no Mackenzie}

A partir do ano de 1964, destacam-se suas pesquisas sobre o campo e participação em eventos. Esses fatos, associados a suas experiências profissionais e acadêmicas, Ihe respaldaram para solicitar ao Mackenzie a criação de um curso de desenho industrial. De acordo com documentação encontrada (Figura 2), tal pedido é identificado desde 1966, e no ano seguinte, há registro de seu desacordo com o "atual andamento da escola" ${ }^{10}$, no qual ele apresenta uma série de recomendações sobre o novo curso, inclusive uma minuta preliminar a respeito.

Nas anotações de Levi ${ }^{11}$, encontramos uma sequência (2. Introdução; 3. Interiores: artesanato e indústria; 4. Interiores como Comunicação; 5. Metodologia: coleta de informações, análise dos dados obtidos, determinação de um "set"de soluções possíveis, evaluação e otimização para escolha da solução, desenvolvimento da solução adotada, controle; 6 . Tipologias - áreas burocráticas e administrativas, comerciais - lojas, clubes e recreação coletiva, residência, arquitetura promocional;

\footnotetext{
${ }^{7}$ Idem.

8 Idem.

${ }^{9}$ Constatamos ainda em suas anotações, por meio de documentação extraída de acervo de Marília Levi, uma série de anotações de Lívio a respeito de suas visitas, presente nas cartas encaminhadas à diretora do Mackenzie quanto ao desejo de melhorias do curso de arquitetura e de implantação de um curso independente de desenho industrial.

10 Carta de Lívio Levi a Salvador Cândia, diretor da FAU Mackenzie, em 08/05/1967. [Fonte: Acervo de Marília Levi].

${ }^{11}$ Caderno de Notas. [Fonte: Acervo de Marília Levi].
} 
detalhes diversos; 7. Iluminação; 8 . Trabalhos Práticos ${ }^{12}$ ) para sua disciplina em que, apesar de não se oferecer identificação sobre como e o quê foi aplicado em suas aulas, devido à ausência de data, percebe-se uma coerência com o relato de sua aluna quanto ao conteúdo apresentado em sala de aula.

UNIVERSIDADE MACKENZIE

FACULDADE DE ARQUTTETURA

SAO PAULO - BRASH

of. ne $1016 / 66$

São Paulo, 5 de Dezembro de 1966
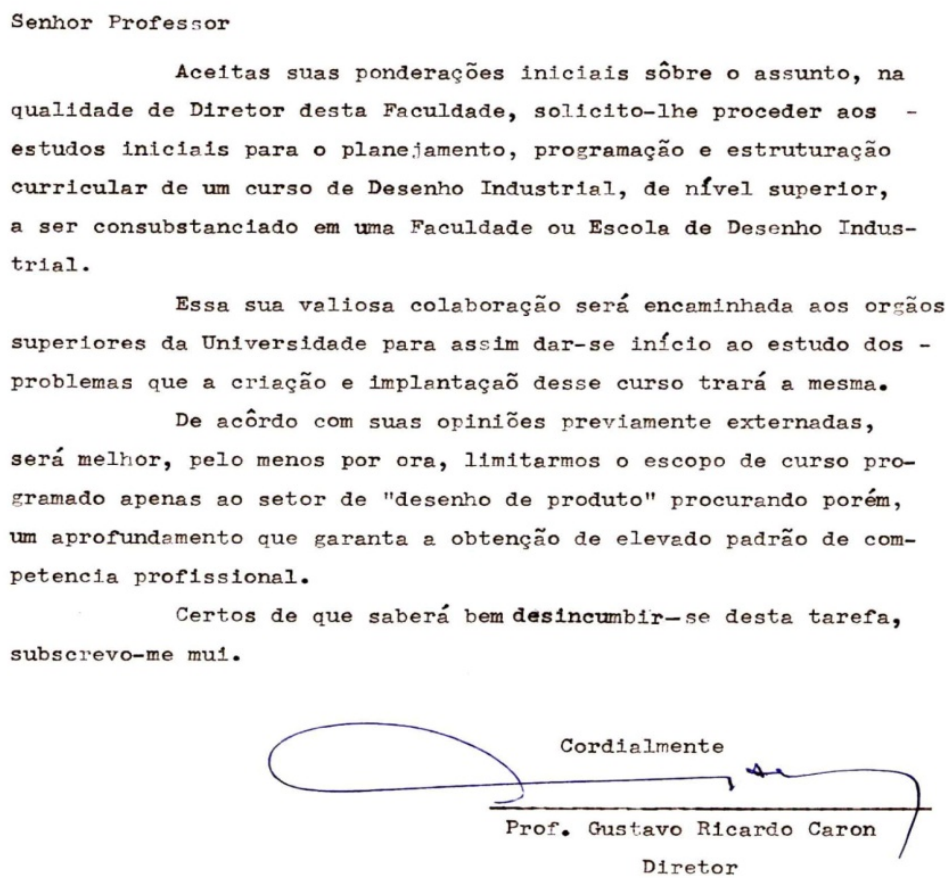

"Figura 2 - Carta do diretor da FAU/Mack, Gustavo R. Caron, ao professor Lívio Levi”.

Fonte: Acervo de Marília Levi.

$\mathrm{Na}$ cronologia nos escritos do professor, esta sequência no caderno de anotações pessoal situa-se após os apontamentos da viagem aos EUA, o que, se considerarmos que elas começaram no período inicial de sua carreira como docente no Mackenzie, provavelmente houve certa influência internacional na montagem do curso independente de desenho industrial que estava propondo à Escola.

Considerações sobre os conteúdos e formatos desejados são encontradas em cartas destinadas à diretora da Faculdade de Arquitetura, em que cita, em grande parte, a organização do curso do IIT como exemplo a ser seguido.

Nas páginas próximas a tais relatos, anotações sobre semiótica, psicologia e teoria da informação também são encontradas frequentemente em seu caderno de notas, e um exemplo de que houve a tentativa de implantação desse conteúdo pode ser identificado no trecho extraído de mesmo acervo, onde coloca: “Não entenderam aula de semiótica. Diferença de signo, sinal e símbolo (dar nova aula, dar exemplos)"13.

12 Caderno de Notas. [Fonte: Acervo de Marília Levi].

13 Anotações de Lívio Levi sobre sua impressão de uma possível aula com abordagem em Semiótica. [Fonte: Caderno de notas. Acervo Marília Levi]. 
A influência da área da semiologia no design e a alusão ao conteúdo da teoria da Comunicação é observada nas notas de Levi, que também se dedica, em grande parte delas, a apresentar alusões a escolas, professores e métodos internacionais e nacionais. A partir do início do ano de 1966, há referência a nomes, como Max Bense, Umberto Eco e Décio Pignatari, e a proposta de inserção da psicologia da percepção e da comunicação no conteúdo programático para o curso sugerido. $E$, com esta proximidade com os aspectos semânticos do design, o professor expõe a crença de que "o objeto também é portador da mensagem"14.

Assim, por intermédio das anotações no caderno e outros documentos, verificamos a aspiração de Levi pela abertura de um curso pleno de graduação de desenho industrial. Ele cita a urgência desta implantação, devido ao desenvolvimento do campo industrial paulistano, em carta aos dirigentes do curso. Essa foi uma das ações empreendidas durante a fase em que ele esteve como professor no Mackenzie marcado por esse anseio.

A partir das idas do professor ao exterior, fortaleceu-se a crença nele da necessidade de criar em São Paulo, no âmbito universitário, instituições apropriadas para o ensino de design em seus vários campos de atuação, como o desenho industrial e a comunicação visual.

Para o caso do Mackenzie, o professor relata em uma de suas cartas que já estaria anunciada uma implantação de "departamentos" na faculdade, que isto permitiria maiores possibilidades de criação de cursos e que aquela era uma ocasião adequada para se pensar na implantação do curso de desenho industrial.

Neste período (por volta de 1966), Lívio Levi apresenta um esquema que situa a "Escola de Industrial Design" no contexto de uma Universidade. Nesses apontamentos, dentre os principais tópicos encontra-se que a organização das aulas deveria abranger a definição sobre design e a relação de igualdade e diferença com o desenho, acesso aos campos de conhecimento, os processos de informação, formação e comunicação; conhecer o conceito de várias ciências e interligações; semiótica, cibernética, matemática e teoria da informação.

No seu caderno, encontram-se também anotações de tópicos (1. Análise elementar e desenho de produto simples; 2 . Desenho de produto simples; 3 . Projeto de equipamento para uso em direta relação com o corpo humano; 4. Projeto de objetos complexos para uso humano + oficina; 5 . Desenvolvimento de projeto completo desde análise escrita até modelo final; 6 . citados abaixo) para um curso de Projeto de Produto, mas impossíveis de identificar se são referentes às aulas que assistiu no exterior ou a um programa montado por ele para as aulas no Brasil. No entanto, tais notas dão indícios de uma organização baseada nos moldes das escolas americanas visitadas.

1. Análise elementar e desenho de produto simples

2. Desenho de produto simples

3. Projeto de equipamento para uso em direta relação com o corpo humano

4. Projeto de objetos complexos para uso humano + oficina

5. Desenvolvimento de projeto completo desde análise escrita até modelo final

\footnotetext{
14 Caderno de Notas. [Fonte: Acervo de Marília Levi].
} 
6. Solução de um projeto de objetos que estendem ou melhorem operações + oficina (protótipos)

A viagem aos EUA ${ }^{15}$ proporcionou a Levi observar a importância que era dada aos exercícios práticos dentro do curso de Desenho de Produto e fez com que ele trouxesse esta experiência para o Brasil e declarasse suas intenções segundo esta linha de pensamento para um futuro curso na Universidade Mackenzie.

Assim, destaca a Oficina como espinha dorsal do IIT, declara a importância conferida à abordagem conceitual mais que à tecnologia e à estética e relata a significativa participação dessa escola na sociedade americana, com seus alunos já saindo com emprego nas indústrias americanas; também acrescenta: "partindo da livre experimentação da tradição bauhausiana, o ID hoje (final da década de 1960) está no caminho de sua definição básica dos aspectos pedagógicos do ensino do design" ${ }^{16}$.

\subsection{Fundação Armando Álvares Penteado - FAAP}

A Fundação Armando Álvares Penteado - Faap possuía certo prestígio na sociedade na década de 1960 devido às suas atividades voltadas às artes plásticas e ao talento de profissionais que já faziam parte do corpo docente. Assim, a intenção de Lúcia e Roberto Pinto de Souza em criar cursos de ensino superior foi posta em prática a partir do aproveitamento de suas instalações. A visão do casal diante das condições de incentivo à indústria possibilitou a criação da primeira Faculdade da Fundação: a Faculdade de Artes Plásticas e Comunicações, cuja finalidade e importância estão assim descritas:

Com a criação da Faculdade de Artes Plásticas e Comunicações, a direção da Fundação pretendia formar uma cultura artística não só em ateliês e na criação de obras, mas também teórica. As aulas começaram em fevereiro de 1967 e eram dadas no mesmo prédio do museu. Sinal de prestígio, a aula inaugural foi dada pelo então governador do Estado de São Paulo, Roberto de Abreu Sodré. [...]. (MATTAR, 2010, p. 132)

Nestas condições, as bases dos futuros cursos de design da instituição foram lançadas. No entanto, abalizando-se os depoimentos obtidos, esta mudança foi mais no âmbito dos nomes das disciplinas do que da prática pedagógica.

Pintura, Gravura, Desenho, Escultura, entre outros, dão um panorama dos cursos que eram lecionados antes de 1967 e que continuaram depois da abertura da Faculdade. Com os dois primeiros anos básicos, as aulas, como estas acima, e outras como Estilística e Composição formavam os cursos de Desenho e Plásticas, Comunicação Visual e Desenho Industrial. Com grande conteúdo de disciplinas voltadas às artes, destoavam, em certa medida, das necessidades desses cursos, nos quais as questões relativas à indústria e suas técnicas seriam abordadas.

Nestas circunstâncias, é importante salientar que as disciplinas do ciclo profissional e técnico em projeto e oficinas, provavelmente, demandaram mais contribuições externas à FAAP, sendo a principal fonte encontrada os arquitetos que atuavam no campo disponível do design (como móveis, impressos gráficos e interiores), entre estes encontramos o professor Lívio Levi.

15 Outros dados sobre a ida de Levi aos EUA, contatos estabelecidos e decorrentes apontamentos estão apresentados nos Anexos desta publicação.

16 Caderno de Notas. [Fonte: Acervo de Marília Levi]. 
Após a revisão dos cursos da Faculdade de Artes Plásticas devido à paralisação de 1968, Lívio Levi foi chamado pelos dirigentes da FAAP a integrar seu corpo docente. Este período coincide com as tentativas frustradas do professor em implantar um curso de desenho industrial no Mackenzie, enquanto a FAAP já o fizera e buscava adequar seu ensino aos anseios da comunidade acadêmica e com a legislação. Vale assinalar que em 1969 é apresentado o Currículo Mínimo para os cursos de Desenho Industrial e a Fundação Armando Álvares Penteado buscava adaptar-se às exigências. A contratação de Lívio Levi contribuía para suprir profissionais para as disciplinas de projeto, enquanto o Mackenzie, cuja Faculdade de Comunicação e Artes era proveniente da Arquitetura contava com arquitetos e engenheiros para lecionar em suas disciplinas.

Levi levou consigo Daniel Lafer ${ }^{17}$, e juntos continuaram a promulgar o desenho industrial, não mais como uma disciplina isolada dentro de um curso de Arquitetura, mas componente de um curso específico de Design e contribuíram para preencher a dificuldade de encontrar docentes para as disciplinas mais técnicas.

\section{CONCLUSÃO}

Nesse contexto de busca por referências no campo acadêmico e profissional do desenho industrial, ressalta-se a ação do professor Lívio como um personagem que trouxe importantes considerações desse campo ao Brasil. Sua importância para o ensino do design paulistano é identificada por suas participações nos eventos promovidos pelas distintas entidades da área do período.

As anotações do seu caderno de notas e documentos encontrados expõem provavelmente um resumo dos pensamentos de Levi e sugerem as ideias que ele expunha à Faculdade de Arquitetura do Mackenzie em meados da década de 1960. Seus conteúdos mostram que era constante a troca de mensagens entre o professor e os dirigentes da Instituição, sobre a abertura de um curso exclusivo de desenho industrial.

Entre os diálogos, verifica-se, por um lado, uma permissão restrita ${ }^{18}$ concedida pelo Mackenzie para que Levi buscasse informações do novo curso, como na carta do diretor da FAU/Mackenzie, Prof. Gustavo Ricardo Caron, ao professor Lívio Levi, em 05 de dezembro de 1966 (Figura 2). E, por outro, um desconforto do docente quanto às instalações e condições encontradas na Escola para receber o curso pretendido, conforme conteúdo da carta destinada ao diretor da Faculdade, Salvador Cândia, escrita por Lívio Levi em 08 de maio de 1967 (Figura 3).

\footnotetext{
17 Daniel Lafer, arquiteto formado pela FAU/USP em 1956, discípulo de Lívio Levi no campo da docência em 10 anos no Instituto Presbiteriano Mackenzie e, posteriormente, até o ano de 1990 na FAAP. Autor de um grupo significativo de luminárias.

18 Ofício No. 1016/66 enviado do diretor substituto Gustavo Ricardo Caron a Lívio Levi no ano de 1966. [Acervo de Marília Levi].
} 


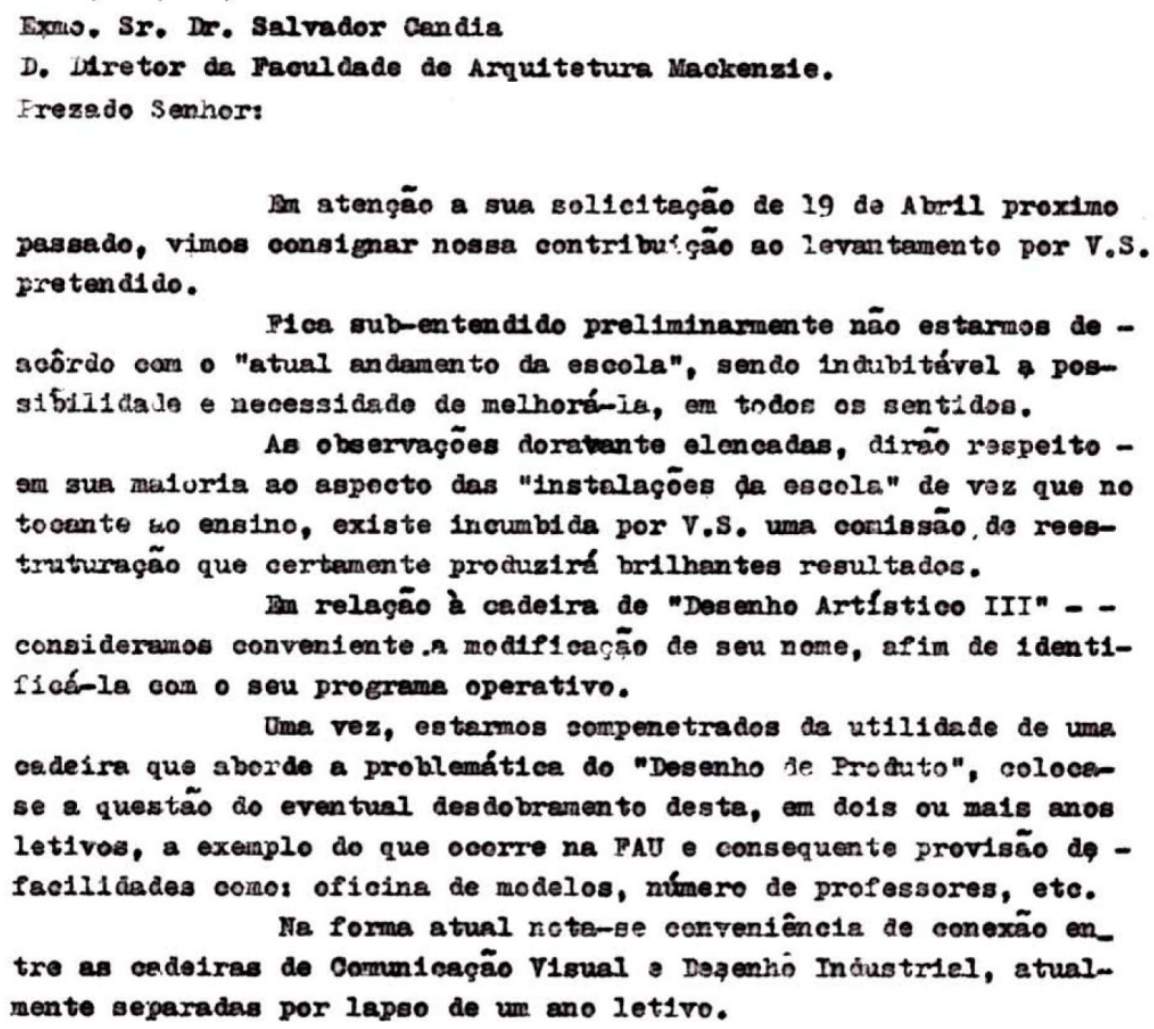

“Figura 3 - Trecho extraído da Carta do professor Lívio Levi ao Diretor da Faculdade de Arquitetura e Urbanismo do Mackenzie, Salvador Cândia".

Fonte: Acervo de Marília Levi.

Ao longo desse período, são observadas as críticas feitas pelo professor às condições de infraestrutura da Faculdade de Arquitetura e as sugestões indiretamente pontuadas para a implantação de um curso regular específicos de Desenho Industrial e Comunicação Visual, fazendo-se necessária a aproximação dessas duas cadeiras. No final da década de 1960, dentro do curso de Arquitetura, a disciplina de DI era ministrada apenas no terceiro ano, enquanto o primeiro e o segundo ano possuíam disciplinas de Comunicação Visual.

Cada vez mais presente nas questões relacionadas ao design, o professor Levi continuou a participar de congressos, exposições e concursos, nacionais e internacionais; contudo, seus apontamentos indicam que não havia uma correspondência de suas ideias com as dos responsáveis pelos cursos do Mackenzie quanto à importância que era dada a esta área de atuação. Indícios da posição assumida pela Instituição em adiar a implantação do curso de DI são encontradas em alguns documentos e notas do acervo familiar de Lívio Levi.

Assim, durante o ano de 1969 encontram-se pedidos de afastamento do curso feitos pelo professor, para que pudesse cumprir compromissos em outras atividades relacionadas ao design ${ }^{19}$. Pedidos estes que, por vezes, Ihe foram negados. Não obstante essas condições, seu afastamento é confirmado em 19 de março de 1970.

${ }^{19}$ Caderno de Notas. [Fonte: Acervo de Marília Levi]. 
Frente a essas atitudes, uma suposição seria pensar que, inspirado nos exemplos de outras escolas, nos trabalhos profissionais de arquitetura e de projeto de produto e em suas pesquisas sobre o design, Lívio Levi poderia estar buscando, fora da academia, uma maneira de valorizar o campo. No entanto, os registros documentais sugerem que também havia uma questão de incompatibilidade entre seu interesse e a relevância conferida ao DI pelo Mackenzie e não à academia em si.

Tanto que no ano de 1970 é confirmada, por meio de documentação (Figura 4) sua presença em outra Instituição em que se ministrava design, a FAAP, e conforme declara sua ex-aluna Esther Stiller ${ }^{20}$ :

[...] provavelmente [Lívio Levi] teria buscado a FAAP como um caminho que poderia mudar o curso e melhorar a atividade industrial [...] foi convidado a dar aula logo em seguida quando saiu do Mackenzie [...] em 1971 já tinha

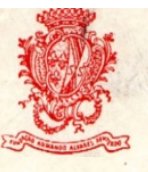
estagiários da FAAP no escritório.

FACULDADE DE ARTES PLÁSTICAS E COMUNICAÇōes

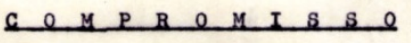

Declaro, pelo presente, que me comprometo a exercer as funções de Professor Titular da disciplina: "Desenvolvimento do Projeto I (Desenho Industr1al)", - na Faculdade de Artes Plásticas e Comunl cações da Fundação Armando Alvares Penteado, no horár1o estabelec1do pelo D1retor dessa Faculdade, - caso seja aprovado pelo Colep do Conselho Federal de Educagão como titular da referida discipli na. Declaro, outrossim, que năg há Incompatibilidade de horários que me impossibilite o cusprimento dêste compromisso.

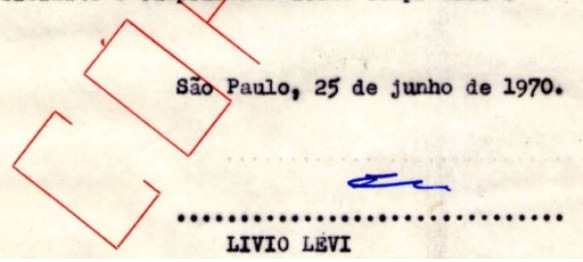

“Figura 4 -Declaração de Compromisso como professor titular, de Lívio Levi para com a FAAP". Fonte: Acervo de Marília Levi.

Por não estar explícito nas informações encontradas como teria se dado o desfecho da relação entre o professor e o Instituto Presbiteriano Mackenzie, torna-se inviável afirmar quais as consequências exatas de sua contribuição ao curso de Desenho Industrial que foi implantado em seguida. Contudo, sua presença em vários acontecimentos do campo e o contato com outros profissionais da área produziram ideias que foram apresentadas ao Mackenzie e, provavelmente, discutidas posteriormente pelos demais docentes que permaneceram na Instituição.

Levi não vivenciou diretamente a implantação dos cursos de Comunicação Visual e Desenho Industrial, pois não fazia mais parte da Escola em 1971, quando estes foram abertos. No entanto, quando se comparam seus registros com a grade inaugural do curso, pode-se estabelecer uma influência parcial no grupo de desenho industrial, principalmente devido à correlação entre terminologias, conceitos, ordenações e estruturas curriculares, pelos quais podemos supor que Levi foi um importante precursor dos cursos de desenho industrial e comunicação visual no Mackenzie.

Sua tentativa de inserir um curso de desenho industrial nesta escola, a busca pelo aprimoramento dos conhecimentos desta área e o envolvimento com as questões

20 Entrevista de Esther Stiller concedida à autora em 28/08/2011. 
do desenho industrial tornam Lívio Levi um dos principais agentes de aplicação das ideias de design dentro desta Instituição. Tais fatos fizeram com que nesta pesquisa fosse considerado como precursor dos empreendimentos para se abrir um curso de desenho industrial no Mackenzie.

A atuação de Lívio Levi na academia do design - por meio da busca de referências no ensino e apresentação de propostas para o campo, identificada nos acontecimentos e em seus registros - evidencia um pensamento à frente de seu tempo. Nas suas propostas de curso para o Mackenzie, citava a inserção de disciplinas dirigidas a percepção e semiótica, a apresentação de exercícios com complexidade crescente ao longo do curso e a integração com a indústria,

Em seus registros ${ }^{21}$, Levi mostrou-se um defensor do desenho industrial. Há neles tentativas de informar aos dirigentes do Mackenzie algumas definições do campo do desenho industrial/design e, ainda, seus esforços na busca de conhecimento sobre como implantar um curso fundamentado, o que é verificado pela quantidade de cartas destinadas à Instituição com esse intuito durante a década de 1960.

Os ambientes dos encontros nos campos de design e de arquitetura permitiam o convívio entre os agentes que dirigiam suas atividades à prática do desenho industrial, e Levi era um dos assíduos frequentadores. Apesar de não se poder categorizar que a proximidade com professores de outras instituições de ensino tenha sido primordial para as sugestões feitas pelo professor Levi ao Mackenzie, o contato com outros profissionais, provavelmente, foi um dos fatores que contribuíram para geração das propostas de abertura de um curso independente de DI.

Assim, apesar de sua relevância e pioneirismo no campo da iluminação (tema abordado e em andamento de outra pesquisa desta autora), a participação de Lívio Levi no desenho industrial brasileiro vai além da elaboração de projeto de produtos. 0 arquiteto foi atuante junto às primeiras associações dedicadas à profissão e à academia.

\section{REFERÊNCIAS}

BRAGA, Marcos da Costa. ABDI: História Concisa da Primeira Associação Profissional de Design do Brasil. Revista D: design, educação, sociedade e sustentabilidade, v. 1. Porto Alegre: UniRitter, 2007.

MATTAR, Denise (org.). Memórias reveladas: A atuação cultural da FAAP 1947-2010. São Paulo: FAAP, 2010.

Produto e Linguagem. São Paulo: Associação Brasileira de Desenho Industrial, 1은 trimestre, 1965. Ano 1, n.1.

STILLER, Ester. Entrevista concedida à autora em 28/08/2011.

${ }^{21}$ Escritos de Lívio Levi. [Acervo de Marília Levi]. 